\title{
Sustainable Digital Access to Cultural Heritage: Organizational, Financial and Policy Challenges
}

\author{
Eva Van Passel \\ IBBT-SMIT, Vrije Universiteit Brussel \\ Pleinlaan 2, 1050 Brussels, Belgium \\ eva.van.passel@vub.ac.be
}

\section{INTRODUCTION}

Sustainable digital access to cultural heritage has become an important policy goal and field of research. In Flanders (Belgium), a collaborative interdisciplinary research project is being carried out that looks into challenges posed by sustainable digital archiving and access as they affect cultural, educational and scientific sectors. This presentation focuses on the challenges that need to be overcome on an organizational, financial and policy level within this research project, Archipel.

\section{ARCHIPEL: A NETWORKED APPROACH}

Actors such as libraries, archives and museums all have the common goal of safeguarding access to their materials. Collaboration between these actors in the digital age has many benefits, but is also difficult to achieve (Zorich, Waibel \& Erway, 2008; Van Oost \& Coppens, 2010). Archipel departs from a networked approach and therefore requires collaboration: content from different sources is aggregated with collaborative preservation and distribution as the aim. Further distribution via e.g. Europeana is foreseen in the technical architecture.

\section{THE NON-TECHNICAL CHALLENGES}

Alongside technical challenges, there are important organizational, financial and policy issues to be tackled. A first issue this presentation will focus on is valorisation. Previous research in Flanders has looked at financing models for the digitisation life cycle (Moons, Van Passel \& Nulens, 2009). The importance of societal value of access to culture determines the (un)desirability of certain revenue models: valorisation goes beyond revenue issues. Nonetheless, economic sustainability is highly important. A second related issue is the challenge of reaching and engaging audiences. Audience strategies should not only focus on the visibility of individual institutions or collaborative initiatives, but should have wider societal value. Organisations and policy makers have an important role to play in tackling these challenges.

\section{CONCLUSION}

In sum, the fundamental question of what memory institutions should mean, now and in the future, is at stake. The presentation concludes that there is a strong need for additional fundamental research on institutions' changing roles and collaboration between libraries, archives and museums.

\section{ACKNOWLEDGEMENTS}

Archipel is funded by IWT (Agency for Innovation by Science and Technology) in the PIM framework (Programme Innovative Media), http://www.iwt.be/. For more information on the project and partners, please consult http://www.archipel-project.be/.

\section{REFERENCES}

Moons, A., Van Passel, E. \& Nulens, G. (2009) Eindrapport: Financieringsmogelijkheden en modellen voor de digitalisering van cultureel erfgoed. Departement CJSM, Brussels.

Van Oost, O. \& Coppens, S. (2010) Haalbaarheidsstudie voor het opzetten van een Vlaamse horizontale, cross-sectorale metadata aggregator voor het digitaal cultureel erfgoed. Departement CJSM, Brussels.

Zorich, D., Waibel, G. \& Erway, R. (2008) Beyond the Silos of the LAMs. Collaboration Among Libraries, Archives and Museums. OCLC Programs and Research, Dublin, $\mathrm{OH}$. 